\title{
Teaching Vocabulary Through Wiki to First Secondary Graders
}

\author{
Khalid Yahya E. Al-Johali ${ }^{1}$ \\ ${ }^{1}$ Department of Curriculum and Instruction, Umm Al-Qura University, Mecca, Saudi Arabia. \\ Correspondence: Khalid Yahya E. Al-Johali, Department of Curriculum and Instruction, Education College, \\ Umm Al-Qura University, Mecca 21955, Saudi Arabia.
}

Received: February 23, 2019 Accepted: April 3, 2019 Online Published: April 6, 2019

doi: 10.5539/elt.v12n5p42

URL: https://doi.org/10.5539/elt.v12n5p42

\begin{abstract}
Vocabulary is a fundamental component of any language. Learning vocabulary plays a crucial role in learning English language. Whereas wiki is a promising Web 2.0 technology that can be used innovatively in EFL instruction. This study aimed at examining the effectiveness of wiki-based instruction on vocabulary learning of first secondary graders. It was carried out in Sabya, Jazan, Saudi Arabia in 2018. It followed the quasi-experimental design of one experimental group. Fifty-seven Saudi teenage EFL students participated in a researcher-designed wiki-based vocabulary course in a random male school. The course consisted of twelve lessons to teach 80 words picked from the grade's English Schoolbook (Mega Goal 2) to ensure their importance and benefit to students. Vocabulary pre-test and post-test along with a closed observation card were used to collect data. Descriptive statistics, paired samples and one-sample t-tests were used for analysis. It was found that wiki had slight positive effect on vocabulary learning. Results demonstrated that students achieved significantly better marks in their post-test but with a very low effect size (0.32). In addition, wiki was observed as usable, motivating, vocabulary enlarging assistant, and can be perceived positively by students. In the contrary, it was observed that the students' collaborative work level was low. Accordingly, wikis can be a good vocabulary teaching tool if well-designed and well-implemented after training both teachers and students.
\end{abstract}

Keywords: Wiki, vocabulary learning, EFL, collaboration, motivation

\section{Introduction}

Among online computer applications, wiki emerged as a rising and promising technology that is gaining more popularity in education because of its diverse capabilities that can provide an engaging social collaborative environment. The wiki was first created by Ward Cunningham in 1994 to be a social collaborative tool. In the last decade, wikis began to be seen increasingly in language classrooms mainly for collaborative writing. Wiki is a rich word processing-like website that can be used to assign many various instructional tasks. The simplicity of its creation and use introduces it as a powerful educational tool. Wiki allows almost every user to freely contribute easily to its content. Furthermore, multimedia means can be uploaded easily (Arnold et al., 2012, p. 432; Halsey, 2012, pp. 1-3).

Teaching vocabulary is very fundamental for language learning since its importance is proved by many studies such as Ho (2011) and Spencer et al. (2012). However, the status of teaching English in Saudi Arabia is very disappointing. Technology may provide many possibilities to enhance EFL learning in general. Vocabulary learning has been the core of many CALL programs. Nowadays, the internet can provide rich online multimedia-mediated means for vocabulary learning and instruction (Kun, 2011, p. 525).

\subsection{Problem Statement}

In the era of globalization and ICT revolution, learning English becomes a crucial demand for anyone who wishes to convoy the accelerated changes in the world. The researcher wanted to investigate the role that wikis can really play in learning English vocabulary. Wikis attracted him because of their increasing use and popularity in education. He thought that for teenage secondary graders, it is easy to use a wiki more than any other complex online application. Many services underlie a wiki website that can be explored and well activated by language teachers (Bin et al., 2012, pp. 100-104; Hadjerrout, 2012, pp. 46-49; Li et al., 2012, pp. 160-165; Yusoff et al., 2012, pp. 91-94).

On the other hand, teaching vocabulary is very important for language learning. It is emphasized that learning vocabulary plays a central role in the whole show of EFL teaching (Hassan, 2012, p. 327; Limin \& Qian, 2012, p. 
117). Words are the bricks of language building. Vocabulary can ease communication, comprehension, fluency and achievement. In addition, if the vocabulary store is larger, the performance in language skills will be better. Moreover, it is believed that the problem of this study springs from students' low achievement in English tests, their demotivation and weak interaction in English classes.

\subsection{Study Questions}

\section{Main Question:}

What are the effects of using wikis in EFL instruction on vocabulary learning of first secondary graders in Sabya Governorate, Saudi Arabia?

Sub-Questions:

1). Is wiki usable, simple and easy-to-use in vocabulary learning?

2). What can wiki do to motivate students to learn English vocabulary?

3). What is the effect of the vocabulary wiki on students' collaboration?

4). How can wikis assist students acquire new vocabulary?

5). How do students perceive the using of vocabulary wiki?

\subsection{Objectives}

This study aimed at accomplishing these objectives:

1). To examine the impact of using wikis on vocabulary learning of Saudi EFL secondary learners.

2). To investigate their attitudes towards wiki-based vocabulary instruction.

3). To help make vocabulary learning environment more interesting, enjoyable and motivating.

4). To explore new dimensions of using wikis in EFL instruction and suggest implications to develop them.

\subsection{Significance of the Study}

This study may be important for:

1). Language teachers: It could help them using wikis to teach vocabulary. It might shift their eyes to the potentials of wikis.

2). Language learners: It may encourage them to learn vocabulary more easily and enjoyably through wikis.

3). Teacher educators: It could stimulate educators' interests in designing training courses for language teachers to develop their skills in using wikis educationally.

4). Syllabus designers: It might highlight the practicality of wikis in vocabulary learning to prompt them to take wikis into consideration when designing EFL syllabuses.

\subsection{Definitions of Terms}

- Wiki: A website of multiple pages that allows almost anyone to edit, add, modify and even delete its content. The word "Wiki" came from a Hawaiian word for quick. (Dudeney \& Hockly, 2007, p. 171).

- Vocabulary: The body of words used in a particular language (Oxford Dictionaries, 2018).

- Usability: The degree to which something is able or fit to be used (Oxford Dictionaries, 2018).

- Motivation: The psychological feature that arouses an organism to action toward a desired goal; the reason for the action; that gives purpose and direction to behavior (vocabulary.com, 2018).

- Collaboration: Working together to do a task. It involves sharing ideas, exchanging information and working in groups. Whereas cooperation involves dividing the work on a group members and working on each part specifically and independently. (Hadjerrouit, 2012, p. 47).

- Attitude: A feeling or opinion about something or someone, or a way of behaving toward him or it driven by that feeling or opinion (Cambridge Dictionary, 2018).

- WBVI: Wiki-Based Vocabulary Instruction.

- TVI: Traditional Vocabulary Instruction (Grammar-translation/audiolingual paper-based methods).

\subsection{Delimitations}

This study was executed in Sabya Governorate and in one male secondary school. So, its results might not apply to all first secondary graders in Saudi Arabia due to sample smallness, shortness of wiki experiment, exclusion of 
female students and the largeness of Country's area and population.

\section{Literature Review}

\subsection{Using Wikis in Language Instruction}

Many studies proved that using wikis is effective in enhancing students' language learning, satisfaction, motivation, confidence and tendency towards EFL learning. Students were able to interact with each other via group works in a social collaborative environment to complete instructional tasks and improve their language. The attitudes of language learners towards wiki-based collaborative language learning were favorable. Students perceived wikis as a useful tool to facilitate their language learning. Moreover, language wikis managed to create an atmosphere of comfort and enjoyment among most EFL/ESL learners (Alshumaimeri, 2011, p. 755).

Learning a foreign language required students to exert more effort and spend more time even outside the classroom. They can find extra help on one website, the language wiki, which can be a resource of language learning activities or has hyperlinks to other enriching vocabulary websites. Learning a foreign language might be boring especially for weak students. Wiki is an innovative growing technology. So, it can help language instructors create an interesting engaging collaborative language learning environment. Such rich environment can help students improve their language skills and learn the target language from different resources such like peers, instructors, websites, online dictionaries and podcasts. Wikis proved to be promising for teaching vocabulary.

Most studies discussed their effects on writing ability since writing skill is the most difficult among language skills and require writers to exploit all their language competencies. So, it is a good indicator of language proficiency. Here are some studies that discussed the use of wikis in language instruction.

Begining with Alshumaimeri (2011) who found that wikis' students outperformed non-wikis' ones. Therefore, he concluded that wikis could help both teachers and students by improving their writing skills in terms of accuracy and quality in a collaborative environment. It was evidenced that wikis would hopefully help students and teachers grow their aptitudes and acceptance of creativity in language learning.

Yusoff et al. (2012) discovered that students managed to work together online without major problems. Wikis were useful for storing data and collaboration and helpful for completing assignments. Wikis encouraged group participation by raising students' motivation. Argumentation appeared concerning the preference of face-to-face or online discussion. Wiki was facilitative and beneficial.

Mohammed (2013) found using wiki to be effective in developing writing skill and reducing apprehension of university students. Wiki offered usable enjoying collaborative environment that motivated participants to engage effectively in activities. Concludingly, wiki could provide a flexible, friendly and confidence-raising atmosphere for collaboration, knowledge creation and interaction.

Aydin (2015) reviewed the literature and concluded that using wikis improves language skills, enhances positive perceptions of learning, increases motivation, provides opportunities to practice autonomy, and enhances inquiry learning and critical thinking. Wikis are advantageous tool for improving writing, and may assist developing literacy in multilingual contexts. However, they have no effect on cultural awareness.

Çelik and Aydin (2016) experimentally examined the effects of wiki-based writing environment on writing achievement of 42 Turkish EFL learners. Background questionnaire, a writing achievement pre- and a post-test were administered. Results indicated that using wiki online increased writing achievement regarding content. Wikis should be integrated into EFL learning process due to their advantages.

Krasnova et al. (2016) sought to understand if wikis could enhance online collaboration and positively affect students' attitudes to collaborative work. 48 undergraduate Russian students enrolled in General English Blended Course. The success of wikis is strongly dependent on the proper wiki design. The finding displayed that wikis are great potential for transforming education to be learner-centered. Most students viewed wikis as valuable encouraging collaborative tools for exchanging ideas.

Ansarimoghaddam et al. (2017) qualitatively compared learner-learner interaction on wiki and face-to-face in-class collaborative writing. Thirty ESL tertiary students were randomly divided into Group 1 (wiki) and Group 2 (face-to-face). Data were collected through wiki writing processes, face-to-face audio-recordings, and semi-structured interviews. The findings revealed that both groups displayed similar understanding, and learned from each other through developing and sharing different perspectives. Meanwhile, wiki is a more effective for drafting and revising, while planning is done easily face-to-face. Both methods can be used alone or in a blended learning environment. 
Kassem (2017) investigated the effect of using wikis on developing business writing skills and reducing writing anxiety. Sixty students at Prince Sattam University, KSA were randomly chosen and divided into control and experimental groups. Test of Business Writing Skills (TBWS) and Writing Anxiety Inventory (WAI) were used. Wikis has positive significant effects on developing business writing skills and reducing writing anxiety of EFL learners. Recommendably, instructors should be trained on how to integrate wikis in writing instruction.

Sánchez-Gómez et al. (2017) explored 358 pre-service teachers' perspectives towards the use of wikis and discussion boards to improve writing skills in English and promote autonomous and collaborative learning in a B-learning environment. Mixed methods approach was adopted. The results suggested pre-service teachers' positive perception of the e-activities, feeling more confidence. They liked the collaborative opportunities offered by wikis such as creating collective texts and discussion boards which provide a dynamic learning environment.

Vahedipour and Rezvani (2017) investigated the effects of providing wiki-based interactive feedback on improving the grammatical accuracy in writing and the attitudes toward receiving wiki-based feedback. 50 secondary Iranian EFL learners were chosen and divided into experimental (Wiki) and control (paper) groups. Results revealed that using wiki had significant positive effect on improving students' grammatical accuracy in writing. Most learners welcomed the application of wiki for EFL writing. Same results were found in Iksan and Halim (2018).

Akbari and Erfani (2018) compared the effect of wiki and e-portfolio on writing skill of Iranian secondary EFL learners. 81 participants attended 14 sessions in two experimental (wiki and e-portfolio) and one control (paper-based) groups. The results revealed that applying wiki and e-portfolio were significantly more effective in learners' writing than the conventional way. Wiki could encourage higher levels of progress in writing skill.

Awada and Diab (2018) investigated the effectiveness of Google Earth and Wiki in improving oral presentation skills and boosting motivation. $81 \mathrm{EFL}$ learners were distributed on control and experimental groups. Factorial mixed methods pre-test/post-test design was employed. The findings stressed that Google Earth and Wiki could facilitate active learning with information, and promote student-centered learning and motivation. They improved learners' oral presentation skills and perceptions. Wiki could increase scaffolding and collaboration. Google Earth could facilitate critical thinking and spatial analytical operations.

Hudson (2018) examined the use of wiki to develop ESL writing skills. Thirteen international ESL/EFL students a Scottish University were placed on a two-week online course to discuss the use of wikis in learning L2. The course used Wikispaces, an educational wiki. Data were collected through a questionnaire, interviews and the teacher's diary. It was found that wikis might assist students' writing. Most students liked to work collaboratively on wiki.

$\mathrm{Su}$ et al. (2018) investigated the occurrence of self and social aspects of regulation during wiki-supported collaborative reading activities in EFL context. Sixty Chinese college students organized in twelve groups. Integrated method of content analysis and sequential analysis was used. Results indicated that all groups demonstrated active social regulation in the collaborative wiki-based activities. Moreover, high-performing students displayed distinctively different patterns of regulatory behaviors.

\subsection{Wiki-based Vocabulary Instruction}

Although very few studies inspect the influence of wikis on improving vocabulary learning but wikis still have something to do in this field. The effectiveness of wiki technology as a tool for language learning and instruction was proved by many studies. Wikis have the potentials to support vocabulary instruction. Wiktionary is an apparent example of vocabulary wikis that can be used for learning and teaching vocabulary. Students can work collaboratively under their teacher's supervision to set up a classroom vocabulary wiki that can work as a learning resource and a simple dictionary. So, the role of vocabulary wikis is promising and straightforward if teachers managed to utilize them well in their classrooms. Here are some studies that discussed using wikis in vocabulary instruction.

Martin (2011) noticed that wikis could help contextualize vocabulary and grammar through the functions of storing and hyperlinking. Students' engagement in wiki homework depended mainly on students' ICT skills. They felt encouraged by online comments, their language proficiency also improved. Wiki succeeded in hosting homework assignments, easing submission and providing quick and relevant feedback. Furthermore, students and lecturers saw it as a useful support for learning and teaching. He recommended using homework wikis largely in education.

Khany and Khosravian (2014) investigated the use of Wikipedia to teach and learn vocabulary. 36 secondary 
Iranian EFL students equally assigned to control and experimental groups. Results divulged that Wikipedia learners surpassed their traditional peers. Wikipedia is an encouraging authentic resource to assist EFL learners in improving their vocabulary knowledge.

Eren (2015) experimentally examined the use of Web 2.0 tools (including wikis) to improve EFL students' vocabulary knowledge. 45 Turkish students at Gaziantep University were selected and assigned into experimental (23) and control (22) groups. Semi-structured interviews, field notes, pre-test and post-test were used. Results demonstrated that the experimental group significantly excelled the control one. Most students had positive attitudes towards using Web 2.0 tools.

Since wiki is a website, Hajebi et al. (2018) sought the effect of web-based language learning on improving vocabulary knowledge and attitudes toward using web-based language teaching. 66 pre-secondary Iranian EFL learners were equally divided into control and experimental groups. Modified Michigan test was used as pre-test and post-test. Result manifested that learners' perception was improved. Experimental group significantly outperformed control group in vocabulary knowledge. Their attitudes ameliorated, too.

Hussain (2018) experimentally examined the effects of ICT-based learning using wiki on seventh graders' vocabulary mastery at junior high school in Bandung. 50 students were equally divided into experimental and control groups. Vocabulary pre-test and post-test, and a wiki were applied. The findings revealed that there were significant differences between experimental group and control group. He recommends teachers to provide interesting topic, let students chat online, assign homework, and well prepare the facilities before starting.

\subsubsection{Studies With Negative Findings}

In spite of many studies that supported the use of wikis in education, there were some critic studies that might reveal the negative side of wikis or the hardships that may arise while working on them.

Halsey (2012) found that although students scored better results in science vocabulary and content but he did not quantitatively observe a significant indication of the effectiveness of wikis on improving students' science vocabulary and understanding science content. Despite that, he proved qualitatively that wikis could increase behavioral and cognitive engagement, interest and enthusiasm of students towards science. He continued that though wikis seemed easy-to-use but his students found difficulties to use such a new technology which might cause frustration and setbacks. However, he witnessed some students who felt comfortable while working with wikis. Despite those results, he still believed in wikis.

Wang (2012) discovered that using wikis for collaborative writing in a college classroom was not as efficient as originally hypothesized. Students preferred to revise their own writings and neglect their peers'. He further suggested that wikis could be used as a knowledge management system better than using wikis as a collaborative tool. Despite that, he said that wikis could improve writing ability.

Alshalan (2016) sought to determine the impact of wiki-based collaborative writing on ESL students' writing performance. 24 international students in a private American university were divided into control (13) and experimental (11) groups. Timed writing essay, demographic survey, pre-test and post-test were used. The results showed insignificant improvement among the experimental group. Additionally, the experimental group significantly outperformed the control group in three dependent variables: vocabulary, grammar, and mechanics.

\section{Method}

\subsection{Study Design}

This was a quasi-experimental study with one experimental group using pre-test and post-test beside an observation card.

\subsection{Setting and Context}

This study was carried out in Sabya Governorate, Jazan Province, Saudi Arabia during the first term of the school year 2018. Sabya third secondary school in Sabya town was randomly selected. It has good facilities and a helpful principal. There were two instructional laboratories with good internet connection to be used to accomplish the experiment. The researcher selected the first secondary grade to conduct the study. There were two classrooms in this stage. Their 57 students were adopted to participate in the experiment.

\subsection{Population and Participants}

All male first secondary graders in Sabya Directorate of Education constituted the population. They were about two thousand male students according to the official statistics shown in the official website: edu.moe.gov.sa/Sabya/Pages/default.aspx. 
The sample was selected randomly due to the random selection of the school. It consisted of 57 Saudi EFL students who had been studying English for the fifth successive year. They were between 15 to 18 years old. They were regarded as one experimental group.

\subsection{Instruments of the Study}

\subsubsection{Vocabulary Pre-test and Post-test}

The first instrument was two alike vocabulary tests, a pre-test and a post-test, that were designed by the researcher in light of Coompe et al. (2012) to test vocabulary knowledge. The two tests contained five different vocabulary questions. They were objective tests consisting of two multiple choice questions, filling in question, picture naming question and synonyms matching question. Each test had six items in each question, 30 items on aggregate. Each test was corrected out of 30 marks, a mark for each item.

To check their reliability, the researcher applied both tests on different sample of 20 students for each test in a different secondary school before executing them on the participants. Then he used the split-half reliability method to measure the reliability coefficient. The reliability coefficients were $0.83>0.70$ and $0.81>0.70$ which were acceptable statistically.

To verify their validity, sheets were sent to ten EFL/TESOL specialists working in higher and public education to check the convenience of both tests to the objectives and content of the course, and the clarity of the instructions. The researcher took all remarks into consideration and developed the tests accordingly.

\subsubsection{Observation Card}

It is used to support the tests' results and answer the study's sub-questions. During the short vocabulary course periods, the fellow teacher observed his students and their interactions while working on the vocabulary wiki. By using it, he checked the degree of wiki usability, students' motivation, collaboration, attitudes, and their vocabulary improvement. In light of Isa $(2012$, p. 127), the researcher prepared an observation card to do so. It was validated by seven experts. To check the card's reliability, he used the observers' agreement method (the researcher and his colleague). Using Cooper's equation, the total agreement percentage was $84 \%$ (high reliability).

\subsubsection{Wiki-based Vocabulary Course}

To execute the wiki-based teaching experiment, a small vocabulary course was designed by the researcher based on first secondary English school book of the second term (Mega Goal 2) that is taught in the province. He chose that textbook to neutralize the effect of the continuing teaching process of the existing syllabus.

It was intended to teach 80 different words extracted from the second term book's six units whose topics are: “It's a You've Got Mail, Wishful Thinking, Complaints-Complaints, I Wonder What Happened, If It Hadn't Happened, and What They Said". Seven words were picked equally from each unit. The course consisted of twelve lessons with 7 words to be taught in ten lessons beside two periods for introduction and revision. He designed these lessons and composed their activities benefitting from the wiki functions and many English teaching websites such as iteslj.org, vocabulary.com, education.com, abcya.com and britishcouncil.org. The course lasted three weeks, four periods a week.

The researcher created a vocabulary wiki on Wikispaces for the research. Its address is voc1439.wikispaces.com. The vocabulary course was designed offline using MS Word before conveying the final draft to the wiki website. It consisted of eleven pages: Home, What is wiki?, Lessons 1-10, Vocabulary games, and Vocabulary websites. It also contained illustrating presentations and podcasts for learning and enrichment.

The vocabulary wiki website was refereed by five experts and adjusted following their valuable notes.

\section{Results}

\subsection{Pre-test and Post-test Results}

As shown in diagram 1 below, most students scored better results in the post-test. However, seven students scored the same mark in both tests, whereas only two students scored worse mark in his post-test. In addition, the best mark in the pre-test was 17 while the worst was 6 . In the post-test, the best mark was 19 while the worst was seven.

We observe from table 1 that the post-test mean (11.42) is higher than the pre-test mean (12.60). This clarifies that the students slightly scored better results in the post-test after studying vocabulary through the wiki. It is observable that the median was the same.

Paired samples T-test was carried out to check the significance mean difference (1.175). The value of $t$ is 10.217 
and the significance value is $0.00<a=0.01$. So, it can be decided that there is a significant difference between the two means in favor of the post-test's one since its mean is higher. This result proves statistically that the performance of students in the post-test excelled their performance in the pre-test.

Table 1. Pre-test and post-test descriptive statistics

\begin{tabular}{llllll}
\hline Statistics & & \multicolumn{3}{c}{ Correlation } \\
\hline $\mathrm{N}=57$ & Mean & Standard Deviation & Median & $r$ & Sig. \\
Pretest & 11.42 & 2.618 & 12 & .948 & .000 \\
Posttest & 12.60 & 2.725 & 12 & & \\
\hline
\end{tabular}

Table 2. Results of paired samples t-test

\begin{tabular}{|c|c|c|c|c|c|c|c|}
\hline \multicolumn{7}{|c|}{ Paired Samples T-Test } & \multirow{3}{*}{ Effect Size } \\
\hline \multirow{2}{*}{\multicolumn{2}{|c|}{$\mathrm{N}=57$}} & & & & & Sig. & \\
\hline & & Mean & Standard Deviation & $\mathrm{t}$ & $\mathrm{df}$ & (2-tailed) & \\
\hline Pair 1 & Pretest-Posttest & 1.175 & 0.869 & 10.217 & 56 & .000 & 0.32 \\
\hline
\end{tabular}

The researcher calculated the effect size coefficient (Cohen's d) directly using the correlation coefficient (r) of T-test following this equation:

$$
\text { Cohen's d }=\frac{2 \mathrm{r}}{\sqrt{1-\mathrm{r}^{2}}}
$$

Cohen's $d$ value is 0.32 which is considered low according to Cohen (1988). This indicates that using the wiki has a low effect on students' vocabulary learning.

\subsection{Observation Card Results}

During the course, the fellow teacher observed his students using the card. According to the observation card, students worked on Wiki quite easily. Wiki managed to motivate students to learn vocabulary. But it failed to enhance collaborative learning. The teacher observed a slight improvement in students' vocabulary. Finally, positive attitudes towards vocabulary wiki were noted.

Applying one-sample t-test for significance issues, all means of the five axes were found significant in the significance level $(a=0.01)$.

Table 3. Observation results statistical analysis

\begin{tabular}{lllll}
\hline Axis & Standard Mean=1.5 & M & t & Sig. \\
\hline A) Wiki Usability. & & 1.8 & 6.67 & .001 \\
B) Motivating Wiki. & 2 & 10.01 & .000 \\
C) Students' Collaboration while Using Wiki. & 1.3 & -3.43 & .018 \\
D) Students' Ability to Improve their Vocabulary through Wiki. & 1.9 & 5.54 & .002 \\
E) Students' Perception of Using Wiki. & 2 & 8.66 & .000 \\
\hline
\end{tabular}

\section{Discussion and Conclusion}

\subsection{Answering the Sub-questions}

5.1.1 Is Wiki Usable, Simple and Easy-to-use in Vocabulary Learning?

The results of Axis A of the observation card reveal that the students found the vocabulary wiki to be simple and easy-to-use. They perceived wiki as a helpful learning tool whether inside or outside the classroom. This result has a strong support from previous studies like Hadjerroutt (2012), Mohammed (2013) and Li et al. (2011). 
To clarify, simplicity and usability differ from one wiki host website to another. Wikispaces was selected because its interface and functions are simple, clear and handy. Anyway, almost all wiki host websites are created to be simple and easy to access, use and edit. It is the teacher's roles that made the difference (Arnold et al., 2012; Bin et al., 2012; Pellet, 2012). Without teacher's interferences, students could face more obstacles that may lead them to frustration and to be reluctant (Halsey, 2012).

Actually, students encountered technical hardships while working on wiki. These technical problems attributed to their ICT incompetency (Hadjerrouit, 2012; Halsey, 2011; Lin \& Yang, 2011). This indicates that students need to be well trained before applying wikis in the classroom to help them benefit a lot from such a social collaborative website.

\subsubsection{What Can Wiki do to Motivate Students to Learn English Vocabulary?}

If we look at Axis B results in table 2, it can be assumed that wikis are an effective tool to enhance students' motivation to learn vocabulary and English in general. Same findings can be read in many studies such as Arnold et al. (2012), Awada and Diab (2018), Aydin (2015), Isa (2012), Mohammed (2013).

Wiki technology proved widely to be motivating due to its novelty and modernity that arouse curiosity to discover and use it. Curiosity in turn makes wiki students more motivated and committed to complete the given vocabulary activities. Actually, English teachers in Saudi Arabia are suffering a lot to promote their students' motivation that will be reflected in their language learning. Wiki can be the solution for motivation problems since it can motivate even low-performing students (Isa, 2012, p. 94).

The researcher justifies this result by saying that ICT competency plays a crucial role in enhancing motivation. High digitally-competent students tends to learn more about and through wikis while low competent ones feels frustrated and out of the show. So, they tend to resist using wikis (Arnold et al., 2012, p. 446; Hadjerrouit, 2012, p. 447).

\subsubsection{What Is the Effect of the Vocabulary Wiki on Students' Collaboration?}

In light of Axis $\mathrm{C}$ results, we find that the wiki has failed to provide a good environment for collaborative vocabulary learning despite the fact that wiki technology was basically created to be a social collaborative tool from its birth. So, it is supposed theoretically to enhance collaboration. This may be because of time limits that may prevent or delay the development of collaboration mechanics among students. Moreover, the wiki illiteracy of the students might play a negative role and led to such result. In contrast to that, it was empirically proved that wikis can facilitate collaborative learning. Evidences can be observed in Awada and Diab (2018), Krasnova et al. (2016), Li et al. (2012), Martinsen and Miller (2012), Pellet (2012) and Yusoff et al. (2012). This result contradicted most of these studies. Similar negative results were found in Halsey (2012) and Alshalan (2018).

\subsubsection{How Can Wikis Assist Students to Learn New Vocabulary?}

The results of the vocabulary tests and Axis D in tables 1 and 2 indicate that wiki technology can help students learn new words. Despite the shortness in time of the wiki-based vocabulary course but it had done it slightly. It managed somehow to ease the learning of new words. This result is supported by many studies such as Hassan (2012), Kun (2011) and Tamjid and Moghadam (2012).

This result is devoted to the interesting nature that wiki has since it is a technology on one hand, and to the services that wiki can provide for vocabulary learners on the other hand. Such services can correspond different learning styles preferred by students.

In fact, the online read-and-write approach, that the concept of wikis is based upon, can help students develop their vocabulary since vocabulary is like the fuel for the vehicles of reading comprehension and writing ability (Pellet, 2012, p. 241). During reading and writing, students need to check up the key words on dictionaries or by asking their peers. Thus new words can be learnt and practiced in a collaborative learning environment. Teachers also can design a vocabulary wiki and embedded it with hyperlinks to online dictionaries, vocabulary websites, vocabulary games, YouTube videos. Presentations, videos, and podcasts can be gathered, too (Eren, 2015; Hajebi et al., 2018; Hussain, 2018; Khany \& Khosravian, 2014; Martin, 2011).

\subsubsection{How Do Students Perceive the Using of Vocabulary Wiki?}

As detecting from Axis E results, students perceived wiki positively. The researcher argued that wiki can change the general perspectives of Saudi EFL learners to be more positive than they are. Many previous studies evidenced the helpful role of wiki technology in this issue such as Alshumaimeri (2011), Isa (2012). In general, people look positively at technology as a progressive and interesting thing. Nowadays, English is a necessity to comprehend and use computers and internet properly. The online exposure to vocabulary through wikis can 
assist the implicit foreign language learning. Thus a change in the negative perspectives will happen out of focus. We can interpret that the attractiveness of the learning medium could lead to consider what is learnt.

In fact, one of the most annoying problems that English teachers are facing in Saudi schools is the prevailing negative look towards English. The researcher noticed throughout his teaching experience that many students show indifference, weariness or reluctance during English periods. Many factors stand behind that problem such as teachers' improficiency, societal attitude towards English and peers negative ex-experiences. Using wiki technology can be the solution because it can renew and add to EFL/vocabulary learning settings (Ali et al., 2012, p. 24; Hajebi et al., 2018).

\subsection{Answering the Main Question}

What are the effects of using wiki in EFL instruction on vocabulary learning?

The results have quite proved that wiki technology has a slight positive effect on students' vocabulary learning. The indications in this study and what was found in the literature prove that wikis are supportive and prospective. They can be useful in vocabulary classrooms. Besides, they are an efficient teaching tool that language teachers can exploit in various ways to enhance vocabulary learning and give students opportunities to learn outside the classroom. Eren (2015), Hajebi et al. (2018), Hussain (2018), Khany and Khosravian (2014), Martin (2011) strengthen this finding However, since wiki is an online technology, its assumed effect on vocabulary learning was proved implicitly in various studies such as Fehr et al. (2011), Hassan (2012), Kun (2011) and Tamjid and Moghadam (2012).

How much effective is the vocabulary wiki? In fact, looking at table 2 shows a low effect size of the wiki (0.48) although there was a significant difference between the means of the pre-test and the post-test in favor of the latter. Why is that? The shortness of the wiki experiment, which lasted for 15 days, may reduce the effect size to that low. In addition, both the teacher and the students may need to be trained on using the wiki sufficiently. Also, that low effect size can be attributed to ICT incompetency and the absence of teacher's role. This result matches what Alshalan (2016), Elabdali (2016), Halsey (2012), and Wang (2012) has found.

Though the low size effect that the vocabulary wiki achieved but the researcher thinks that wikis can do it because of their various potentialities. They can work as a platform to link students with various authentic vocabulary websites that can enlarge their vocabulary knowledge. Hyperlinking service is of great usefulness for vocabulary instruction. In addition, many vocabulary podcasts and presentations can be embedded in the wiki website. Information about a word can be shared and sent through wiki to all students (Mideros \& Roberts, 2011, pp. 9-15; Pellet, 2012, pp. 224-230).

\subsection{Conclusion}

Vocabulary has undoubted importance in language learning similar to that of building blocks. The present study investigated the effectiveness of instructional wiki on learning English vocabulary. The final outcome of the study indicated slightly that wiki can contribute to the process of vocabulary learning although the effect size was very low. Beneath the general main outcome, there are other findings that answered the sub-questions of the study. The findings show that the participants found wiki usable and easy-to-use because it is one of the simplest online computer applications. They also revealed that wikis can enhance motivation to learn vocabulary. Besides, students showed positive perceptions towards wiki-based vocabulary instruction. They liked the wiki way of vocabulary instruction. In the contrary, the degree of collaboration was low. The wiki hasn't promote collaborative work among students may be because of the limited time and wikis unfamiliarity.

Since networked technologies are spreading increasingly in Saudi Arabia, the use of language wikis is reasonable and will be helpful. In addition, students can find it easy to access a wiki from different devices such as laptops, PCs, mobiles and iPads. However, it is the crucial roles of language teachers as designers, trainers, organizers, prompters, monitors, assessors and feedback providers that can make a vocabulary wiki more effective and interesting in the classroom and extend its effect outside the classroom. Moreover, students themselves can learn vocabulary on a wiki through the read-and-write strategy by editing, commenting on, discussing words to be learnt and benefiting from many embedded capabilities (Pellet, 2012, p. 228).

\subsubsection{Recommendations and Implications}

Drawing upon the findings of the study, it is recommended to apply vocabulary wikis in EFL classrooms as a supplemental teaching tool, platform for vocabulary learning, classroom dictionary and assessment tool since they are usable, simple and acceptable; creating an official public EFL syllabus-based referential wiki to enhance autonomous vocabulary learning, support classroom work and enrich syllabus content; creating an English classroom wiki to motivate students and enhance collaborative language learning inside and outside the 
classroom; designing appropriate wiki-based collaborative vocabulary learning tasks; and incorporating wiki competency in pre-service and in-service teacher preparing and training programs.

\subsubsection{Future Studies}

The researcher suggests more future studies to explore the effects of using instructional vocabulary wikis on female students, different stages, and blended learning settings.

\section{References}

Akbari, F., \& Erfani, S. S. (2018). The Effect of Wiki and E-portfolio on Writing Skill of Iranian Secondary EFL Learners. International Journal of Applied Linguistics and English Literature, 7(3), 170-180. https://doi.org/10.7575/aiac.ijalel.v.7n.3p.170

Albousaif, M. A. (2011). Factors determining Saudi learners' difficulties in attaining EFL vocabulary. Master thesis, University of Newcastle, Australia.

Alenezi, H. (2014). Vocabulary Instruction Practices of Highly Effective Kindergarten Teachers. Doctoral dissertation, University of Arkansas.

Alghamdi, A. A. M. (2013). Technical vocabulary instruction in a Saudi Arabian industrial college: An investigation of English Language and content area practitioners' beliefs and practices. Doctoral dissertation, University of Essex.

Ali, Z., Mukundan, J., Baki, R., \& Ayub, A. F. M. (2012). Second Language Learners' Attitudes towards the Methods of Learning Vocabulary. English Language Teaching, 5(4), 24-36. https://doi.org/10.5539/elt. v5n4p24

Alshalan, A. M. (2016). The Effects Of Wiki-Based Collaborative Writing On Esl Student's Individual Writing Performance. Doctoral dissertation, Wayne State University.

Alshumaimeri, Y. (2011). The effects of wikis on foreign language students writing performance. Procedia-Social and Behavioral Sciences, 28, 755-763. https://doi.org/10.1016/j.sbspro.2011.11.139

Ansarimoghaddam, S., Hoon, T. B., \& Yong, M. F. (2017). Collaboratively Composing an Argumentative Essay: Wiki versus Face-to-face Interactions. GEMA Online ${ }^{\circledR}$ Journal of Language Studies, 17(2), 33-53. https://doi.org/10.17576/gema-2017-1702-03

Ansarimoghaddam, S., Tan, B. H., Yong, M. F., \& Kasim, Z. M. (2012). Recent Development of Wiki Applications in Collaborative Writing. Theory and Practice in Language Studies, 2(10), 2035-2044. https://doi.org/10.4304/tpls.2.10.2035-2044

Arnold, N., Ducate, L., \& Kost, C. (2012). Collaboration or cooperation? Analyzing group dynamics and revision processes in wikis. CALICO Journal, 29(3), 431-448. https://doi.org/10.11139/cj.29.3.431-448

Awada, G., \& Diab, H. B. (2018). The Effect of Google Earth and Wiki Models on Oral Presentation Skills of University EFL Learners. International Journal of Teaching and Learning in Higher Education, 30(1), $36-46$.

Aydin, S. (2015). Wikis as a tool for collaborative language learning: Implications for literacy, language education and multilingualism. Sustainable Multilingualism, 5, 207-236.

Bin, Z., Xiang, C. H., \& Jeaco, S. (2012). An investigation of the use of wikis in English language learning. Chinese Journal of Applied Linguistics, 35(1), 99-116.

Caruso, G. (2014). The Impact of Wiki-based Collaborative Writing on English L2 Learners' Individual Writing Development. Doctoral dissertation, Portland State University.

Çelik, S. S., \& Aydin, S. (2016). Wiki effect on English as a foreign language writing achievement. Global Journal of Foreign Language Teaching, 6(4), 218-227. https://doi.org/10.18844/gjflt.v6i4.1674

Coombe, C., Davidson, P., O'Sullivan, B., \& Stoynoff, S. (2012). The Cambridge guide to second language assessment. Cambridge University Press.

Crum, C. E. (2017). Influence of Technology on English Language Learners' Vocabulary, Reading, and Comprehension. Doctoral dissertation, Walden University.

Elabdali, R. (2016). Wiki-based Collaborative Creative Writing in the ESL Classroom. Master Thesis, Portland State University.

Eren, O. (2015). Vocabulary Learning on Learner-Created Content by Using Web 2.0 Tools. Contemporary 
Educational Technology, 6(4), 281-300.

Gu, Y. (2011). Vocabulary Teaching in Distance Learning. Theory and Practice in Language Studies, 1(6), 737-739. https://doi.org/10.4304/tpls.1.6.737-739

Hadjerrouit, S. (2012). Investigating technical and pedagogical usability issues of collaborative learning with wikis. Informatics in Education-An International Journal, 11(1), 45-64.

Hajebi, M., Taheri, S., Fahandezh, F., \& Salari, H. (2018). The Role of Web-based Language Teaching on Vocabulary Retention of Adult Pre-secondary EFL Learners. Journal of Language Teaching and Research, 9(2), 372-378. https://doi.org/10.17507/jltr.0902.20

Halsey, S. (2012). Time to wiki: A tool to build students'science vocabulary. Master Thesis, Montana State University at Bozeman, Montana, USA.

Harmer, J. (2015). The Practice of English Language Teaching (5th ed.). London/New York: Pearson Longman.

Hassan, A. M. M. H. (2012). Teaching \& Learning Vocabulary for Reading Skill Development and Utilizing Technology for It. Journal of Educational and Social Research, 2(3), 327-334.

Ho, M. J. (2010). The correlation of the depth of learners' vocabulary knowledge and their reading comprehension. Master Thesis, Ming Chuan University, Taipei, Taiwan.

Hudson, J. (2018). Using Wikis for collaborative writing in the ELT classroom. International Journal of Pedagogy and Teacher Education, 2(2), 413-426. https://doi.org/10.20961/ijpte.v2i2.22906

Hussain, Z. (2018). The effects of ICT-based learning of students' vocabulary mastery at the junior high schools in Bandung. International Journal of Education, 10(2), 149-156.

Iksan, H., \& Halim, H. A. (2018). The effect of e-feedback via wikis on ESL students' L2 writing anxiety level. MOJES: Malaysian Online Journal of Educational Sciences, 6(3), 30-48.

Isa, F. H. O. (2012). The effect of using wikis on improving Palestinian 9th graders English writing skills and their attitudes towards writing. Master Thesis, The Islamic University of Gaza, Palestine.

Johnson, B. L. (2016). Exploring effective vocabulary instructional strategies for ELLs through online professional development. Doctoral dissertation, Capella University.

Kameli, S. \& Baki, R. B. (2013). The impact of vocabulary knowledge level on EFL reading comprehension. International Journal of Applied Linguistics and English Literature, 2(1), 85-89. https://doi.org/10.7575/ ijalel.v.2n.1p.85

Kassem, M. A. M. (2017). Developing Business Writing Skills and Reducing Writing Anxiety of EFL Learners through Wikis. English Language Teaching, 10(3), 151-163. https://doi.org/10.5539/elt.v10n3p151

Khany, R., \& Khosravian, F. (2014). Iranian EFL Learners' Vocabulary Development through Wikipedia. English Language Teaching, 7(7), 57. https://doi.org/10.5539/elt.v7n7p57

Krasnova, T. I., Gorbatova, T. N., Kudryashova, A. V., \& Popova, A. N. (2016). Wiki-based Collaborative Learning Experience in a Foreign Language Blended Course. Ponte, 72(7), 206-213. https://doi.org/10. 21506/j.ponte.2016.7.16

Kun, L. (2011). Web-based vocabulary learning in intensive reading. US-China Foreign Language, 9(8), 524-529.

Li, X., Chu, S., Ki, W., \& Woo, M. (2012). Using a wiki-based collaborative process writing pedagogy to facilitate collaborative writing among Chinese primary school students. Australasian Journal of Educational Technology, 28(1), 159-181. https://doi.org/10.14742/ajet.889

Limin S., \& Qian, D. (2012). How Does Vocabulary Knowledge Affect Chinese EFL Learners' Writing Quality in Web-based Settings?-Evaluating the Relationships Among Three Dimensions of Vocabulary Knowledge and Writing Quality. Chinese Journal of Applied Linguistics (Quarterly), 35(1), 117-127.

Lin, W., \& Yang, S. (2011). Exploring students' perceptions of integrating Wiki technology and peer feedback into English writing courses. English Teaching: Practice and Critique, 10(2), 88-103.

Ma, R. (2012). Vocabulary Proficiency Instruction for Chinese EFL Learners. Theory and Practice in Language Studies, 2(6), 1199-1205. https://doi.org/10.4304/tpls.2.6.1199-1205

MacVane, M. R. (2014). The Effects of Vocabulary Instruction on Meaning Retention of Dialectically Ambiguous and Dialectically Neutral Words for Urban First Grade Speakers of AAE. Doctoral dissertation, Cardinal 
Stritch University.

Martin, D. (2011). An investigation into students usage of an online homework wiki, its effect on language improvement and its benefits as a learning and teaching support for undergraduate German. A Master Thesis, University of Limerick, Ireland.

Martinsen, R., \& Miller, A. (2012). Collaboration through Wiki and Paper Compositions in foreign language classes. IALLT Journal of Language Learning Technologies, 42(1), 72-95. https://doi.org/10.17161/ iallt.v42i1.8503

Mideros, D., \& Roberts, N. (2011). "Post it notes": Students' perceptions on assessment and reflective learning in the foreign language learning process using wikis. Journal of Education, Informatics and Cybernetics, 2(3), 9-15.

Mohammed, M. M. K. (2013). Wiki: An Effective Web Tool to Develop Writing Performance and Reduce Writing Apprehension among English as a Foreign Language Learners. A paper presented at 3rd International Conference For e-learning \& Distance Education, Riyadh, Saudi Arabia, February 4-7, 2013.

Pellet, S. H. (2012). Wikis for building content knowledge in the foreign language classroom. CALICO Journal, 29(2), 224-248. https://doi.org/10.11139/cj.29.2.224-248

Proctor, C. P., Silverman, R. D., Harring, J. R., \& Montecillo, C. (2012). The role of vocabulary depth in predicting reading comprehension among English monolingual and Spanish-English bilingual children in elementary school. Reading and Writing, 25(7), 1635-1664. https://doi.org/10.1007/s11145-011-9336-5

Protopapas, A., Mouzaki, A., Sideridis, G. D., Kotsolakou, A., \& Simos, P. G. (2013). The role of vocabulary in the context of the simple view of reading. Reading \& Writing Quarterly, 29(2), 168-202. https://doi.org/10.1080/10573569.2013.758569

Sánchez-Gómez, M., Pinto-Llorente, A., \& García-Peñalvo, F. (2017). The Impact of Wikis and Discussion Boards on Learning English as a Second Language. A Mixed Methods Research. Digital Education Review, 32, 35-59.

Sidek, H. M., \& Rahim, H. A. (2015). The Role of Vocabulary Knowledge in Reading Comprehension: A Cross-Linguistic Study. Procedia-Social and Behavioral Sciences, 197, 50-56. https://doi.org/10.1016/j. sbspro.2015.07.046

Spencer, E. J., Goldstein, H., \& Kaminski, R. (2012). Teaching Vocabulary in Storybooks: Embedding Explicit Vocabulary Instruction for Young Children. Young Exceptional Children, 15(1), 18-32. https://doi.org/10.1177/1096250611435367

Su, Y., Li, Y., Hu, H., \& Rosé, C. P. (2018). Exploring college English language learners' self and social regulation of learning during wiki-supported collaborative reading activities. International Journal of Computer-Supported Collaborative Learning, 13(1), 35-60. https://doi.org/10.1007/s11412-018-9269-y

Tamjid, N. H., \& Moghadam, S. S. (2012). The Effect of Using Vocabulary Teaching Software on Iranian Secondary Efl Learners' Vocabulary Acquisition. World Applied Sciences Journal, 19(3), pp. 387-394. Doi: 10.5829/idosi.wasj.2012.19.03.1164

Vahedipour, Z., \& Rezvani, E. (2017). Impact of Wiki-based Feedback on Grammatical Accuracy of Iranian EFL Learners' Writing Skill. International Journal of Foreign Language Teaching and Research, 5(20), 111-124.

Wang, C. M. (2012). An investigation of using wikis as a collaborative tool for teaching in a non-western tertiary education classroom. Journal of Educational Technology Development and Exchange, 5(1), 63-76. https://doi.org/10.18785/jetde.0501.05

Winchester, S. (2015). On the Scope of Digital Vocabulary Trainers for Learning in Distance Education. Doctoral dissertation, The Open University, UK.

Yusoff, Z. S., Alwi, N. A. N., \& Ibrahim, A. H. (2012). Investigating students' perception of using wikis in academic writing course. 3L; Language, Linguistics and Literature, The Southeast Asian Journal of English Language Studies, 18(3), 91-102.

Zhang, J. (2015). English vocabulary teaching in Chinese junior high schools. Master thesis, Purdue University, West Lafayette, Indiana, USA. 


\section{Copyrights}

Copyright for this article is retained by the author(s), with first publication rights granted to the journal.

This is an open-access article distributed under the terms and conditions of the Creative Commons Attribution license (http://creativecommons.org/licenses/by/4.0/). 